\title{
Esquema argentino de Antonio Candido
}

\section{Adriana Amante}

Universidad de Buenos Aires New York University en Buenos Aires

\section{Resumo}

$\mathrm{O}$ artigo tenta trabalhar algumas linhas propostas por Antonio Candido em Literatura e sociedade em relação com a sua própria obra e com alguns textos fundamentais da crítica literária da Argentina, para poder pensar de novo - a partir do decisivo aporte do crítico brasileiro - alguns problemas que se planteiam também na literatura daquele país.
Palavras-chave

Dialética;

Crítica;

História da

literatura;

Argentina;

Escritura

\section{Abstract}

The essay explores some ideas proposed by Antonio Candido in Literatura e sociedade in connection to his own work and to some other fundamental texts of Argentine literary criticism. The goal of the essay is to think again - from the point of departure of the decisive contribution of the Brazilian critic - some problems also developed in literary texts of that other country. 
Evidentemente, las artes y los actos de enseñanza son, en el sentido propio de este término tan denostado, dialécticos.

George Steiner, Lecciones de los maestros

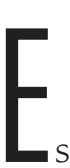

tanto lo que se ha escrito sobre la obra de Antonio Candido en el Brasil que no resulta fácil abordarla de nuevo. Sin embargo, para los argentinos todavía queda un resto que justifica el atrevimiento. Porque pese al voluntarismo ideológico que implicó, primero, la publicación en la revista Punto de Vista del reportaje que le hizo Beatriz Sarlo en 1980; tres años después, la inclusión de "Estrutura social e função histórica" en el libro Literatura/Sociedad, que Sarlo escribe con Carlos Altamirano; y -más acá - el libro organizado en 2001 por Raúl Antelo para el Instituto Internacional de Literatura Iberoamericana de la Universidad de Pittsburg (como era de suponer, de restringida circulación fuera del ámbito académico), en la Argentina - en el mejor de los casos - se tiene conciencia de la importancia del trabajo de Candido pero no necesariamente conocimiento detallado de sus propuestas y de su profusa y profunda producción. ${ }^{1}$

Al margen de los obstáculos que pueda seguir presentando la diferencia idiomática, y que a esta altura no debería ser una excusa sino un minus, el modo en que Candido produce y publica sus escritos puede servir al mismo tiempo como álibi para seguir manteniéndose en el borde. ${ }^{2}$ Los textos publicados por el crítico brasileño, que son más de quince, no están a disposición, y las librerías y las bibliotecas argentinas no parecen darse por aludidas. ${ }^{3}$

\footnotetext{
${ }^{1}$ Reportaje de Beatriz Sarlo a Antonio Candido, Punto de vista, año 3, número 8, Buenos Aires, marzo-junio de 1980; Beatriz Sarlo y Carlos Altamirano, Literatura/Sociedad, Buenos Aires. Hachette, 1983; Raúl Antelo (ed.), Antonio Candido y los estudios latinoamericanos, Instituto Internacional de Literatura Iberoamericana, Universidad de Pittsburgh, 2001. Muchos de los brasileñistas argentinos, que creemos encontrar la cifra en ese gesto de Sarlo y Altamirano, tal vez seamos concretamente su consecuencia ideológica.

${ }^{2}$ Las antologías de Biblioteca Ayacucho o de Fondo de Cultura Económica, por ejemplo, conjuran en parte esa dificultad: Antonio Candido, Crítica radical, Caracas, Biblioteca Ayacucho, 1991; y Ensayos y comentarios, São Paulo, Editora da Unicamp y Fondo de Cultura Económica, 1995.

${ }^{3}$ Antelo abre el prólogo al texto sobre Candido que organiza considerándolo "un crítico aislado" también en su propia lengua por la cantidad de artículos que todavía están dispersos.
} 
Quiero analizar la trama que Antonio Candido urde siguiendo las ideas que propone, reescribe, expande, retoma, vuelve a poner a prueba, y eventualmente continúa, amplía o corrige. Voy a indagar sobre todo cómo es el método compositivo de la escritura de su pensamiento más que los conceptos teóricos que maneja, que tan brillantemente han sido estudiados por los críticos brasileños; abordaré no tanto sus ideas críticas como su escritura crítica, para analizar en particular Literatura e sociedade o, mejor, para pensar a partir de y en torno a Literatura e sociedade algunas líneas que me parecen fundamentales.

\section{1}

No es que Candido no haya publicado obras concebidas y escritas como una unidad en sí: no otra cosa son la Formação da literatura brasileira (1959) y Os parceiros do rio Bonito (1964), sintomáticamente, un libro por encargo cuya escritura le llevará una década y la edición de su tesis de doctorado en Ciencias Sociales, respectivamente. Pero es por demás conocido que, en general, la obra de Candido va encontrando su forma en artículos que se distribuyen por separado y luego van integrando (el propio crítico va haciéndolos integrar) unidades mayores al paso que sigue pensando y escribiendo, y también editando y reeditando.

En su método compositivo, las nociones de obra orgánica y de obra fragmentaria no se excluyen. Antes bien, podríamos postular la posibilidad de una organicidad de fragmentos. Cuando reedita Vários escritos, en 1995, justifica la reproducción de algún artículo que también está en una inesperada reedición de Brigada ligeira -su primer libro- ("o que significa ter no mercado os mesmos ensaios em dois livros"), puesto que vino a formar un conjunto con otras piezas en un nuevo sistema que prefiere no desmontar.

Porque el método compositivo de Antonio Candido trama una red espaciotemporal. Los artículos y "coletâneas" que se van sucediendo son la condensación, en el espacio del libro, de un momento en que está pensando (aun si diversas cosas) en una más o menos homogénea dirección crítica y teórica. Tal vez de los libros de Candido pueda decirse lo que Michel Foucault de la biblioteca considerada como heterotopía: que son un espacio donde se acumula indefinidamente tiempo. Y si bien no indefinidamente, Candido va cortando arbitrariamente con las publicaciones ese continuum de pensamiento que, incluso cuando vaya desarrollándose y hasta mutando, es un devenir constante de esa acumulación (que parece indefinida) de tiempo. En este sentido, el título de su libro Recortes (de 1993) es bien representativo de ese método de escritura que determina un modo de concepción de unidades y conjuntos y, consecuentemente, de publicación.

En ese continuum con cortes que es la obra de Candido, cuando se aborda uno de sus textos no sólo se siente la necesidad imperiosa de ir, organizada y prolijamente, a ver cómo se inserta en la línea de su producción sino que inevitablemente va asaltando la pulsión por derivar de un artículo a otro, de un libro a otro, buscando las constantes, los cambios, las "retomadas" de sus propias "linhas evolutivas", para decirlo con una expresión que Caetano Veloso ha usado en relación 
con João Gilberto. Porque ningún artículo, por contundente que sea, se clausura en sí mismo.

"Toda nuestra formación teórica y crítica está basada en la idea de sucesión temporal homogénea y con una tendencia a no reconocer las contradicciones. El principio de identidad y de tercero excluido rige siempre nuestros pensamientos", sostuvo Candido cuando un grupo de especialistas latinoamericanos se reunió a discutir la concepción de una historia de la literatura latinoamericana. ${ }^{4}$ Para él se planteaba la necesidad de afrontar con otros hábitos críticos que los que se tenían (y se tienen) el hecho de que existan temporalidades múltiples entre las diferentes literaturas nacionales o incluso entre diferentes manifestaciones literarias dentro de un mismo país. Pero éste no debería haber sido un problema que él no estuviera en condiciones de sortear, porque incluso fuera ya de la cuestión historiográfica son precisamente las contradicciones las que Candido asume de manera explícita (lo que terminará resultando programático no sólo para el contexto brasileño sino -es deseable- para el latinoamericano) en "Dialética da malandragem", artículo publicado por primera vez en 1970, al proponer un juego de interacción entre el polo del orden y el del desorden como clave de funcionamiento del texto que Manuel Antônio de Almeida publica entre 1852 y 1853, que lo es también del de la sociedad en que se produce. ${ }^{5}$

Claro que la idea de la dialéctica como modo de funcionamiento y a la vez como principio constructivo, central en ese texto que resultó determinante, viene proponiéndola y madurándola Candido desde mucho antes, como se ve - por caso - en Literatura e sociedade, libro editado en 1965 pero que reúne textos de 1953, 1954, 1955 o 1961 junto con otros para la fecha inéditos. Varias inflexiones de lo dialéctico, como la propuesta de una interpretación no mecanicista entre medio social e obra, aparecen bien manifiestas ya en ese libro y se suma a otras, por ejemplo, cuando arriesga que

\footnotetext{
"Se fosse possível estabelecer uma lei de evolução da nossa vida espiritual, poderíamos talvez dizer que toda ela se rege pela dialética do localismo e do cosmopolitismo, manifestada pelos modos mais diversos. [...] O que temos realizado de mais perfeito como obra e como personalidade literária (um Gonçalves Dias, um Machado de Assis, um Joaquim Nabuco, um Mário de Andrade), representa os momentos de equilíbrio ideal entre as duas tendências.
}

Pode-se chamar de dialético a este processo porque ele tem realmente consistido numa integração progressiva de experiência literária e espiritual, por meio da tensão entre o dado local (que se apresenta como substância da expressão) e os moldes herdados da tradição européia (que se apresentam como forma da expressão)" ${ }^{6}$

${ }^{4}$ Cf. Ana Pizarro (coord.). La literatura latinoamericana como proceso, Buenos Aires, Centro Editor de América Latina, 1985, p. 43.

5 "Dialética da malandragem" aparece en la Revista do Instituto de Estudos Brasileiros, Universidade de São Paulo, número 8. Véase un análisis de lo dialéctico en Paulo Eduardo Arantes, Sentimento da dialética na experiência intelectual brasileira. Dialética e dualidade segundo Antonio Candido e Roberto Schwarz. Rio de Janeiro, Paz e Terra, 1992.

${ }^{6}$ Antonio Candido, "Literatura e cultura de 1900 a 1945", en Literatura e sociedade. Estudos de teoria e história lietarária. Trabajo con la octava edición: São Paulo, T. A. Queiroz (ed.), 2000, pp. 109-110. 
No otra cosa sucede en "Estructura literária e função histórica", otro de los artículos que componen el libro, en el que Candido trabaja la ambigüedad, no estilística sino "estructural", de o Caramuru, de Frei José de Santa Rita Durão. Hay ahí una Dialética da malandragem en ciernes porque, como lo hará para el libro del siglo XIX, en este texto del siglo XVIII analiza el principio constructivo de una obra que también lo es de una forma nacional. ${ }^{7}$

En "Literatura de dois gumes", conferencia que da en 1966 y de la que editará versiones en 1968 y 1969 para después incorporarlo como artículo en A educação pela noite e outros ensaios, de 1987, aparte de trabajar también la relación entre literatura y sociedad, se pronuncia igualmente sobre la "atitude [crítica] adotada", que "pode ser definida como sentimento dos contrários, isto é: procura ver em cada tendência a componente oposta, de modo a aprender a realidade da maneira mais dinâmica, que é sempre dialética. ${ }^{8}$

Dentro de este contexto de posicionamiento crítico, es posible estimar el verdadero tenor de la valorización que Antonio Candido hace de la obra de Gilberto Freyre, que se deja ver en Literatura e sociedade y se manifiesta declaradamente en "Aquele Gilberto", de 1987, otro de los textos "de caráter circunstancial" que se incluyen en Recortes junto con "Um crítico fortuito", de 1962, en el mismo libro, donde puede encontrarse otra clave de lectura para entender cómo lee y piensa Candido, al observar cómo lee y piensa a G. Freyre. De algún modo marca un antecedente en una posible tradición de "obra de sociólogo e historiador da cultura", como define para el caso del discípulo de Franz Boas. Lo que no significa que deba pensarse a Candido como alguien que hace crítica sociológica, como él se ha encargado de señalar con cierto énfasis en Literatura e sociedade, sino como quien hace crítica, una crítica que no entiende lo social como un factor externo que resulta determinante para la obra sino como lo externo que deviene intrínseco de la obra.

No se encolumna tampoco en la postura "nacionalista" de Freyre, que busca (y prefiere) en las obras literarias aquello que permita descubrir y confirmar lo brasileño, ya que a Candido le interesa menos, por ejemplo, cuándo una literatura se convirtió en brasileña que indagar cuándo el Brasil pudo tener una literatura o, sea, cuándo se dieron y se dan las condiciones para tenerla. Pero sí festeja claramente el modo dialéctico de Freyre trazando una línea que puede recuperarse perfectamente en su sistema crítico dentro del cual el modo dialéctico de funcionamiento de un texto es altamente elocuente acerca del funcionamiento del Brasil:

"Lembremos ainda as grandes imagens diretoras, as imagens gerais que estruturam todo um estudo crítico, como, no que escreveu sobre Alencar, a contraposição entre ambiente aberto do campo e ambiente fechado da sala, encarnando os pólos do brasileirismo e do urbanismo europeizante, mas também da

\footnotetext{
${ }^{7}$ Esa misma ambigüedad es la que permite la doble interpretación histórica que se ha dado del libro: como lusitanista y como indianista.

8 "Literatura de dois gumes". En: A educação pela noite e outros ensaios. São Paulo, Editora Ática, 1989, p. 164.
} 
tirania doméstica e da liberdade revoltosa, segundo os quais se ordena a sua obra. Essas imagens duais abundam em Gilberto Freyre e servem para mostrar o seu movimento dialético e integrador, sempre deslizando entre a casa-grande e a senzala, o sobrado e o mocambo, a ordem e o progresso, a precisão racional e a fantasia, a análise técnica e as liberdades artísticas da intuição e do prazer estético". ${ }^{9}$

Pero, como dije más arriba, su propio pensamiento está dispuesto a hacerse cargo de las posibles contradicciones (de las obras, de los principios constructivos e incluso del propio método crítico) y por eso podemos encontrar en el artículo de 1992 sobre "Navio negreiro" de Castro Alves que incluye en Recortes un avatar donde los contrarios, antes que combinarse dialécticamente, se expulsan sin más. Lo que se conjuga en los enredos urbanos o burgueses de Almeida o Machado de Assis tal vez encuentre en el tema de la esclavitud el límite, donde el "movimento das antíteses, das oposições que não se cruzam nem se unificam, gera estrofes admiráveis". ${ }^{10}$

Tanto la dialéctica que combina opuestos como las antítesis irreconciliables no son cuestiones ajenas a otras literaturas, como es el caso de la argentina. Por eso algunos problemas cruciales del análisis de las obras que la componen pueden pensarse en sintonía con el abordaje de Candido, como él mismo lo propone al considerar al Facundo de Sarmiento (al que llama atinadamente por su título original: Civilización y barbarie) como el inaugurador de una línea de pensamiento latinoamericano en la cual la "reflexão sobre a realidade social foi marcada pelo senso dos contrastes e mesmo dos contrários - apresentados como condições antagônicas em função das quais se ordena a história dos homens e das intituições". ${ }^{11}$

Sin estar filiados explícitamente con Candido, es interesante ver cómo algunos textos clave de la crítica literaria argentina pueden volver a pensarse desde sus propuestas. Por ejemplo, los que Ricardo Piglia escribió sobre Sarmiento. Por un lado, "Notas sobre Facundo" (de 1980), uno de los textos más agudos e iluminadores de la crítica argentina, en el que Piglia considera la barbarie del letrado que cita la cultura europea de modo errado y donde, al analizar focalizadamente el texto de un autor, encuentra -como Candido en Memórias de um sargento de milícias o en Caramuru- el modo de funcionamiento o la cifra de la cultura argentina. ${ }^{12}$ También en "Sarmiento, escritor" (de 1998), donde postula que

"El Facundo viene a establecer una relación imaginaria entre dos universos yuxtapuestos y antagónicos. Los problemas de la forma literaria del libro están concentrados en la y del título. (Nadie tiene

\footnotetext{
${ }^{9}$ Antonio Candido, "Um crítico fortuito (mas válido)". En: Recortes, São Paulo, Companhia das letras, 1993, p. 88. Candido cuenta, además, cuán fascinante le resultaba a su generación el desparpajo con que $G$. Freyre estudiaba la sexualidad y las relaciones familiares.

${ }^{10}$ Antonio Candido, "Navio negreiro" En: Recortes, p. 52.

${ }^{11}$ Antonio Candido, "O significado de Raízes do Brasil". En: Sérgio Buarque de Holanda, Raízes do Brasil. São Paulo, Companhia das letras, 1995, p. 12.

${ }^{12}$ Ricardo Piglia, "Notas sobre Facundo", en Punto de vista, año 3, número 8, Buenos Aires, marzojunio de 1980, el mismo número en que aparece el reportaje de Sarlo a Candido, como ya mencionamos en Florencia Garramuño y Adriana Amante, "Partir de Candido", en Raúl Antelo (ed.), Antonio Candido y los estudios latinoamericanos.
} 
un sentido tan personal de la conjunción como Sarmiento. Su escritura une lo heterogéneo. El polisíndeton es el sello de su estilo.) En ese punto se concentra la tensión entre política y ficción. La política tiende a que esa y sea leída como una 0 . La ficción se instala en la conjunción. El libro está escrito en la frontera: situarse en ese límite es poder representar un mundo desde el otro, poder narrar el pasaje y el cruce". ${ }^{13}$

Por su parte, en un artículo de 1970 -el mismo año de la "Dialética da malandragem"-, Noé Jitrik había visto las "raíces hegelianas" del método de conocimiento que Sarmiento puso en funcionamiento en la postulación de la dicotomía civilización-barbarie y que sin embargo -advierte el crítico-, no prevé una síntesis sino el triunfo de alguno de los términos de la oposición. El sistema de oposiciones ilimitadas (en el que, antes que superación, lo que se plantea es la imposición de optar) es, por su parte, el principio constructivo del libro que Jitrik le dedica al análisis del Facundo. ${ }^{14}$

La afinidad puede volver a encontrarse en el intento de analizar el juego dual de oposiciones en "Cambaceres: adentro y afuera", un texto que Jitrik publica en 1960 y que no sólo podemos conectar con los artículos del brasileño que ya hemos mencionado sino incluso pensarlo en relación con su abordaje de $O$ cortiço, de Aluísio Azevedo, particularmente con el artículo "A passagem do dois ao três (Contribuição para o estudo das mediações na análise literária)", de $1974 .{ }^{15}$ En ambos casos, se está trabajando sobre propuestas naturalistas. Jitrik analiza el gusto por los contrastes que viene del romanticismo pero que ciertas manifestaciones del naturalismo transforman en un sistema que busca conciliar las oposiciones y, aún más, que en Sin rumbo -la tercera y penúltima novela de Eugenio Cambaceres- se convierte en táctica de ocultamiento. La escena en que Andrés, el protagonista hastiado de una vida urbana y una sociedad que no le despiertan ya el menor interés, lleva a su amante a una garçonnière de fachada miserable tras de la cual se abre un ambiente de gran refinamiento moderno ("-iPor qué tan lindo aquí y tan feo afuera? -Porque es inútil que afuera sepan lo que hay adentro"), lejos de resultarle incidental, constituye para el crítico argentino un "núcleo significativo" que marcará una constante en cierta tradición literaria argentina: la que intenta pensar o reforzar el predominio de una clase ante el peligro de pérdida por disolución social por medio de un método de entender la realidad, pero que en la última novela de Cambaceres, En la sangre, con el arribismo social del hijo de un inmigrante italiano, se mostrará cómo puede ser socavado y resquebrajado. El p. 26.

${ }^{13}$ Ricardo Piglia, "Sarmiento, escritor", en Revista de Filología, Buenos Aires, Año XXXI, 1-2, 1998,

${ }^{14}$ Noé Jitrik, "Para una lectura de Facundo, de Domingo F. Sarmiento", en Ensayos y estudios de literatura argentina, Buenos Aires, Galerna, 1970; y Muerte y resurrección de Facundo, Buenos Aires, Centro Editor de América Latina, 1983.

${ }^{15}$ En O discurso e a cidade, de 1993, Candido publicará "De cortiço a cortiço", artículo que escribe en 1973 pero que publicará completo en 1991. Antes, aparecen dos versiones parciales, "A passagem do dois ao três", en 1974; y "Literatura-sociologia", en 1976. 
mayor esfuerzo de Candido en su propio abordaje es "passar do dois ao três" para romper con el estatismo al que la dualidad condena, y recusa el estructuralismo que, fijado en el número dos - lo que puede ser de utilidad para el análisis interno de la obra -, no encuentra el modo de pasar del análisis a la interpretación. La misma preocupación movía pocos años antes a Jitrik en la que él mismo llamó su

\begin{abstract}
"etapa 'sociológica', atravesada por preocupaciones ideológicas y políticas. Pienso que, metodológicamente hablando, lo más importante de esta experiencia es la idea de la 'significación' que toda palabra literaria, que todo gesto formal comporta. [...] Todo esto, además, sale de la experiencia que significó para mí la revista Contorno: [...] así como lo fue para Contorno, en estos Estudios y ensayos se trata de organizar un conocimiento de la literatura argentina pero no sólo eso sino también un conocimiento crítico y no sólo eso sino también se trata de no descartar un orden de sentidos vigentes históricamente desde los cuales o en los cuales pueden recortarse los sentidos que las obras principales de nuestra literatura ponen en movimiento". ${ }^{16}$
\end{abstract}

Candido, al final de su artículo, como quien arenga, propone:

\begin{abstract}
"Todavia, voltemos à análise interna, como ponto de partida para compreender melhor o externo, agora, não como genérico, mas enquanto mundo, vida que nutre a obra. E uma vez chegando neste, podemos refazer o caminho em sentido inverso [...]. Procuro construir um modelo de que desvende a estrutura interna, singular da obra. Há, portanto a possibilidade de um método reversível, que se move nos dois sentidos, e que supere o formal e o não-formal na medida em que chega a este partindo daquele e àquele partindo deste".
\end{abstract}

Ambas posiciones plantean una articulación entre lo social y la obra que no determina una dirección única para la indagación de sentidos. Y para volver al caso específico de Candido, incluso ni siquiera podemos hablar de determinación o condicionamiento, ya que lo que él plantea es que la crítica literaria debe trabajar en el sentido de volver interno lo que es externo. No se trata, como queda bien claro desde Literatura e sociedade, de recurrir a lo sociológico como un agregado, sino de asimilar lo social a la manifestación estética, entender lo social y lo histórico como constitutivos de la estructura formal de la obra que entonces, al ser estructura, deja de ser externo para convertirse en interno. ${ }^{17}$ Es sobre la base de esa concepción que, como bien señala Lígia Chiappini, Candido sostiene la autonomía relativa de la obra literaria sin considerar los hechos sociales funcionando en paralelo y separadamente sino proponiendo la "forma como histórica e social, do aparentemente externo à obra como interno a ela, o social e o histórico, por sua vez, na forma". ${ }^{18}$

${ }^{16}$ Noé Jitrik, Ensayos y estudios de literatura argentina, pp. 7-8.

${ }^{17} \mathrm{Cf}$. particularmente "Crítica e sociologia (Tentativa de esclarecimento)". En: Literatura e sociedade.

${ }^{18}$ Lígia Chiappini, "Os equívocos da crítica à 'Formação"'. En: Maria Ángela D’Incao e Eloísa Faria Scarabôtolo (orgs.). Dentro do texto, dentro da vida. Ensaios sobre Antonio Candido, São Paulo, Companhia das Letras, 1992, p. 171, subrayado en el original. 
Esta postura permite resolver el problema al que la crítica se enfrenta cuando no sabe de qué modo establecer relaciones entre las series: literaria, social, económica, histórica. Pero Candido llegará a decir, profundizando y volviendo más explícitos y claros algunos de los presupuestos iniciales de Literatura e sociedade, que las series no deberían considerarse como algo separado que puede ser puesto en relación, sino como una unidad integrada y totalizadora. Es en "A passagem do dois ao três" que lo dice: no es cuestión de pensar en series discernibles y a las que se pueda eventualmente hacer entrar en conexión. De lo que se trata es de ver la "constituição da estrutura enquanto elaboração da totalidade, que é o mundo, a sociedade".

Así es como puede ver en la dicotomía civilización-barbarie el esqueleto (la palabra que Candido usa es "arcabouço") del Facundo, que será también el de Os sertões, de Euclides da Cunha, ${ }^{19}$ y ve - como Jitrik en Cambaceres - el modo en que un autor, una obra, una sociedad proponen una forma de indagarse y pensarse y de reflexionar sobre la realidad para tratar de entenderla. Jitrik ha visto en el par antinómico, "más que una fórmula feliz, un punto de partida constitutivo de la obra; recorriendo sus transformaciones la obra se incorpora y desnuda sus significaciones esenciales, esa afirmación de un conflicto real que define más que todos los esquemas la historia de mi país". ${ }^{20}$

\section{2}

Antonio Candido piensa el sistema literario entramado con lo social; y es precisamente la indagación de las modalidades, sentidos, direcciones y relaciones de esa trama lo que constituye el objeto de su crítica, y en particular el de su libro Literatura e sociedade. También trabaja la trama sincrónica poniendo la serie en relación diacrónica, esto es: interpelando el desarrollo histórico que construye una

${ }^{19}$ Antonio Candido, "O significado de Raízes do Brasil", p. 12.

${ }^{20}$ Noé Jitrik, "Para una lectura de Facundo", p. 31. No hubo, entre Jitrik y Candido ninguna relación personal, como sí la hubo entre el brasileño y Ángel Rama, cuyas consecuencias intelectuales aborda con minuciosidad Pablo Rocca en su libro Angel Rama, Emir Rodríguez Monegal y el Brasil: dos caras de un proyecto latinoamericano, Montevideo, Ediciones de la Banda Oriental, 2006. Es precisamente en ese libro donde se cita una carta de Candido a Rama -de 1979- donde, en procura de personas interesantes que puedan ir a dar cursos en la Universidade de Campinas y entre los cuales da por sentada la inclusión de Rama, le menciona a Jitrik (p. 351). Cuando le comenté a Jitrik que iba a trabajar algunas relaciones entre sus propuestas críticas y las del brasileño, preguntándole si habían mantenido algún contacto intelectual concreto, dijo que no, pero que había un espíritu de época, que puede encontrar sus puntos de anclaje en el libro América Latina en su literatura, compilado por César Fernández Moreno en 1972, y en el proyecto de la Biblioteca Ayacucho que llevó adelante Rama en su exilio.

Los textos argentinos de Jitrik y de Piglia que incluí en el trabajo (que podría extenderse a otro que también resulta determinante: "Una vida ejemplar: la estrategia de Recuerdos de provincia", el texto de Sarlo y Altamirano que indaga el acceso de Sarmiento a los libros como una cultura de segunda mano), merecerían salir de una circulación exitosa pero restringida al ámbito académico para encontrar, tanto en la Argentina como en Latinoamérica, la consideración y la trascendencia que se merecen. Quiero recordar, además, que así como lo hice para los casos mencionados, puede también trabajarse la vinculación conceptual entre las propuestas de Candido y las de Adolfo Prieto, particularmente la de sus libros Sociología del público argentino, Buenos Aires, Levitán, 1956; y Literatura y subdesarrollo, Rosario, Editorial Biblioteca, 1968. 
tradición (como aquella a la que se refiere cuando trata la "de auditório") ${ }^{21}$; pero también poniendo el foco en la línea consecutiva entre diferentes períodos, donde Candido - lo sabemos claramente ya por Formação da literatura brasileira - no busca el corte sino la continuidad, aun cuando se dé en la sucesión de propuestas diferenciadas, como sucede con su abordaje de la arcadia y el romanticismo. O cuando traza la serie que inicia o Uraguai, de Basílio da Gama, y se continúa con el romanticismo indianista y luego con Os sertões, en "Letras e idéias no período colonial", también de Literatura e sociedade. Y, como se ve en el final de esa misma parte, cuando resume lo que ha venido haciendo, que es abordar las letras y las ideas del Brasil colonial (y los escritores más representativos y aprovechables, según un término que él mismo emplea), "segundo as grandes diretrizes que as regeram" porque así es como aparecen el orden y "certa coerência". ${ }^{22}$

Como en otras tantas ocasiones, al final de este texto, Candido hace un resumen que, por un lado, tiene el afán didáctico que promueve toda repetición. Pero, por otro, se ve que nunca es una repetición sino que, antes que en un mero resumen, se convierte en una summa que vuelve a pensar más esquemáticamente lo mismo que ya ha desplegado (y cuando digo esquema no digo simplificación, sino claridad y síntesis).

A veces, esa summa final se convierte en la síntesis de la síntesis, lo que se vuelve particularmente evidente en "A literatura na evolução de uma comunidade", incluido también en Literatura e sociedade. Si ya el abordaje de movimientos (pensados frecuentemente como momentos) era un nuevo modo de síntesis conceptual de la historia de la literatura vista desde "suas relações com a comunidade", 23 ahora hay una nueva síntesis conceptual de la síntesis conceptual, que hace el esquema más teórico de lo que antes se abordó desde la crítica que hace historia o viceversa, o desde la historia que hace un crítico literario. Ahí ya casi no hay nombres o títulos (algunos de los cuales eran cifra de lo que venía estudiándose, como Oswald o Mário de Andrade o Macunaíma). Ahora, sólo la estructura (eso es un esquema que no es simplista) del desarrollo de la literatura en la historia y la comunidad paulista.

Los esquemas no son ajenos a la forma didáctico-conceptual de la crítica de Candido. Recordemos uno de sus artículos más reconocidos, que se titula precisamente "Esquema de Machado de Assis" (en Vários escritos, 1970), que tiene por origen una conferencia dada en los Estados Unidos en 1968 y que está determinado por el imperativo de la síntesis, que le marca el tono. Es una síntesis que piensa, analiza, elige, organiza y ordena didácticamente, explicando, enseñando. Selecciona algunas cuestiones (la carrera intelectual de Machado, la excelencia de una obra que no trascendió fuera del Brasil) y aborda algunos puntos (como el arcaísmo machadiano que deviene moderno después de la experiencia de la

\footnotetext{
${ }^{21}$ Antonio Candido. "O escritor e o público". En: Literatura e sociedade.

${ }^{22}$ Idem op. cit. Literatura e sociedade, p. 107.

${ }^{23}$ Idem op. cit. "A literatura na evolução de uma comunidade", en Literatura e sociedade, p. 165.
} 
vanguardia), iluminadores también de lo que no aparece, de lo que no se analiza, como una muestra que enseña algo (o sea: que muestra y explica), a partir de lo cual, quien lee puede analizar lo que acá no ha entrado o no ha sido considerado de modo directo o exhaustivo. Ésa (y no la que tiene pretensiones enciclopedistas) es una didáctica bien entendida.

Al margen de ese excelente servicio, no sería impensable que el tono de Literatura e sociedade nos suene ahora un poco arcaico, lo mismo que su diseño y estructura de exposición, que va organizando el material en cuadros (no necesariamente dibujados, pero conceptualmente distribuidos), donde diferencia - por ejemplo - factores internos y externos, enumera y trata brevemente diferentes abordajes sociológicos de la literatura y se esmera en dejar particularmente claras las diferentes funciones de la literatura: total, social o histórica e ideológica. Ese tono y ese orden pueden provenir, no sólo de su desempeño como profesor universitario, que es ciertamente constitutivo de su método crítico, sino que también podrían vincularse con la necesidad de hacer llegar, indicar, mostrar, señalar un nuevo modo de leer, de considerar una obra literaria y una literatura, y de hacer crítica. Al introducir un nuevo método crítico también hay que enseñar qué hacer y cómo hacerlo. En este sentido, Candido es consciente de que en Literatura e sociedade está incorporando y proponiendo aspectos sobre los que no se ha depositado atención antes. El libro aborda un problema que inicia una nueva línea, para la que no sólo no hay (o habrá que construir) una tradición sino que resulta novedosa y distinta, y - no es improbable - incluso perturbadora.

Su didactismo se traslada claramente a otros campos y con gran poder de síntesis es capaz de reproducir los presupuestos básicos de su libro del 65 en el reportaje que le hace Beatriz Sarlo en 1980. Allí expone claramente, por un lado, las funciones (total, social e ideológica) de la obra literaria; ${ }^{24}$ por otro, el proceso estructurante que convierte aspectos sociales en una estructura de palabras que no es un documento sino una obra estética, que ya no es lo mismo que lo real (social o psicológico) porque está marcada por la mediación; e ilumina esto último, que es el objeto central de Literatura e sociedade, con lo que constituye el centro de su reflexión en "Dialética da malandragem": "La fuerza de este libro [se refiere a Memórias de um sargento de milícias] no proviene de su carácter estrechamente documental, sino de su extraordinaria solución literaria. [...] Si considero a la novela como texto documental tengo que admitir que es un fracaso completo", porque no alude ni a la esclavitud ni a la transformación de la ciudad de Río de Janeiro.

Es por eso también que, cuando Candido emprende el estudio del romanticismo, sin duda ya en la Formação da literatura brasileira pero de manera parti-

24 "La función ideológica del poema [es] la apuntada por su autor; [...] la función social es la que se ejerce independientemente de la voluntad del autor; [... la función total [...] sólo puede ser captada en relación con la concepción estética que dota de universalidad a la obra".

Aunque es el subtítulo de una de las partes de Literatura e sociedade, todos los artículos de Candido podrían ser considerados una "Exposição didática". 
cular también en el análisis que hace del movimiento en Literatura e sociedade, puede entenderse que, más que una idea y panorama de un momento histórico cultural, lo que busca comprender es el modo en que una literatura piensa y se propone como sistema orgánico.

El Romanticismo y el Arcadismo constituyen los "momentos decisivos" que el crítico elige analizar en su intento de cumplir con la escritura de una historia de literatura del Brasil: o sea, momentos en los cuales las manifestaciones literarias adquieren "características orgânicas de um sistema"; o, como agrega en Literatura e sociedade: los momentos "que mudam os rumos e vitalizam toda a inteligência". ${ }^{25}$

Admitiendo que usa el término "período", pero que ante todo prefiere dar cuenta de una idea de movimiento, en el sentido de pasaje y comunicación entre fases, como aclara en Formação, en Literatura e sociedade alternará con frecuencia entre los términos "movimiento" y "momento", como se ve en "A literatura na evolução de uma comunidade", que de entrada enuncia algo que no es la primera vez que se trata pero que se repite didáctica y concentradamente: las condiciones para que haya, antes que una literatura brasileña, una literatura.

Si bien coincido con el propio Candido cuando destaca, entre los textos que componen Literatura e sociedade el que Sarlo y Altamirano elegirán para incorporar como apéndice en Literatura/Sociedad, "porque es una demostración práctica de los puntos de vista teóricos. ${ }^{26}$ "A literatura na evolução de uma comunidade" me parece fundamental porque permite ver perfectamente la relación y articulación entre literatura y medio social en el sentido establecido por los presupuestos del texto en el que se incluye. Pero sobre todo porque en él se organiza una historia de la literatura de la ciudad de São Paulo considerada desde el análisis de los agrupamientos que van evolucionando. Uso la palabra del título, aunque debe tenerse en cuenta que en Candido no implica una idea positivista del término; la uso en el sentido más cercano al de la palabra "desenvolvimento" en portugués para ver algo que se desarrolla, pero que en castellano sirve para pensarlo literalmente como lo que se desenvuelve, como quien dice que actúa o que se despliega, y no necesariamente que mejora. Aunque, en el análisis del último movimiento - el Modernismo -, gana la sensación de que algo de otro tipo se consigue, que a algo de otro tipo se llega, como cuando se obtiene un logro. No en sentido de perfeccionamiento sino de consecución. El Modernismo es uno de los momentos decisivos porque lleva el interés del grupo a la "sociedade total", que es a su vez su "fonte inspiradora" y la que le marca los "límites de ação".

Lo que Candido traza en este texto es una breve historia (¿una pequeña historia, como quien dice una petit histoire?) de la literatura de São Paulo. Y, por debajo

${ }^{25}$ Antonio Candido, Formação da literatura brasileira (momentos decisivos), Belo Horizonte - Rio de Janeiro, Itataia, 1993, vol. 1, p. 41; y Literatura e sociedade, p. 112.

${ }^{26}$ Lo dice en el reportaje de Sarlo. También como apéndices al libro de los críticos argentinos entran el que ellos mismos escriben sobre Sarmiento al que aludí y el de Ángel Rama "Indagación de la ideología en la poesía: los dípticos seriados de "Versos sencillos". 
de su apariencia simple, se desenvuelve (se despliega, pero también se alcanza) la profundidad de un abordaje que estudia de nuevo ciertos momentos de la literatura de esa ciudad poniendo el foco en los agrupamientos, lo que permite ver con claridad cómo una cuestión social se vuelve intrínseca a las obras literarias y de qué modo esa perspectiva y ese eje marcan un modo de hacer la (una) historia de la literatura.

Así, nunca se trata de un panorama enciclopédico (uso la palabra "panorama”, cara a Ángel Rama que, si bien parecería no haberla tomado de Candido, como sí hizo con la idea de sistema, en este contexto puede ser considerada un derivado de esa misma idea de sistema, que es un conjunto de obras pero también la articulación entre autor-público-obra). En este caso, si hay nombres es porque aparecen como integrantes o emergentes del grupo en cuestión. Si se dan características del movimiento (que a veces se menciona como "momento") es porque han sido pensadas en relación con el funcionamiento del grupo. ${ }^{27}$

De este modo, los momentos están caracterizados, antes que por fechas (aunque no se omitan), por la configuración de una secuencia organizada por conformaciones grupales para "sugerir o papel das formas de sociabilidade intelectual, e da sua relação com a sociedade, na caracterização das diferentes etapas da literatura brasileira em São Paulo". Entonces, la periodización (tomado el término en un sentido laxo) no sigue el calendario sino los siguientes agenciamientos: "um grupo virtual", "um grupo real", "o grupo se justapõe à comunidade", "a comunidade absorve o grupo", "o grupo se desprende da comunidade".

Ese último momento es el que corresponde al Modernismo. Y aquí Candido da una de las más interesantes definiciones de ese movimiento que se inicia con la Semana da Arte Moderna de 1922. Definición que ayuda a resolver (o a asumir) las contradicciones que puede generar el Modernismo y a superar las incomodidades de las perspectivas críticas que intentan reducir el momento a una cuestión de clase, manifestado en un grupo cerrado de artistas con dinero, al considerarlo un movimiento nuevo que viene a darle a la literatura "amplitude ainda maior, fundando-a, não no gosto e no interesse de um limitado setor da sociedade, mas na vida profunda de toda esta, na sua totalidade" y que "faz da literatura um bem de todos". Aquí se ve otra inflexión de lo social, que articula con sentido político una literatura y una ciudad: "Há uma história de la literatura que se projeta na cidade de S. Paulo; e há uma história da cidade de S. Paulo que se projeta na literatura". Hay aquí una lectura profundamente ideológica de la literatura. Así como en la Formação da literatura brasileira, arcadia y romanticismo son los dos momentos decisivos, en Literatura e sociedade lo son romanticismo y modernismo, y en una afirmación que ratifica la

${ }^{27}$ Algo del espíritu de los bosquejos - como los de Joaquim Norberto de Sousa Silva -, particularmente útiles para la conformación de las literaturas nacionales en la primera mitad del siglo XIX, pervive -me parece- en estas pequeñas historias de la literatura donde hay en juego, por parte del crítico, una misión de compromiso intelectual. 
perspectiva política, sostiene que ésos son "dois momentos em que a cidade se projeta sobre o país, e procura dar estilo às aspirações do país todo". ${ }^{28}$ Aquí se ve, de manera ejemplar, lo que va del S. XIX al XX, como en la Formação se ve el del S. XVIII al XIX.

Lo que podemos aprender de Formação es cómo hacer historia de la literatura sin ser abarcadores y exhaustivos hasta el enciclopedismo o el acopio de datos nimios. Lo que podemos aprender de Literatura e sociedade es, entre tantas otras cosas, cómo hacer crítica haciendo historia de la literatura e historia de la literatura desde una perspectiva crítica. Y cómo leer las obras en la historia y con la historia y no la historia en las obras como algo externo a lo que la obra sería ni como un precipitado documental. Como confirma Ligia Chiappini: "para esse crítico-teórico-historiador, não há crítica fora da história".

\section{3}

La línea temporal del método compositivo de Antonio Candido es, como él pretendía que se admitiera para la historia de la literatura latinoamericana, múltiple y de diferentes ritmos temporales, y está evidentemente marcada por circunstancias específicas de la política brasileña. ${ }^{29}$ Por eso no está de más ubicar algunos de los textos que traté en una temporalidad política para pensar ciertas líneas de la producción intelectual de un crítico comprometido: Literatura e sociedade se publica un año después del golpe militar de 1964. Se publica en 1965, año en el que aun sin aludir a esta circunstancia de modo explícito, sintomáticamente Paulo Arantes se centra para encontrar un hilo conductor, un punto de condensación en su abordaje de la "formação da cultura filosófica uspiana" a través de la gestión cultural de un grupo de académicos que incluye al propio Candido y a su compañera, Gilda de Mello y Souza. ${ }^{30} \mathrm{Y}$ si se tiene en cuenta que, además de la netamente ideológica articulación entre lo estético y lo social, el abordaje crítico dialéctico que empieza a tomar forma y a ganar contundencia en esos primeros ensayos de Literatura e sociedade aparece en dictadura, no resulta tampoco irrelevante el dato de que para el momento en que con la "Dialética da malandragem" alcance su más brillante y sintética formulación, el gobierno militar que no había sido del todo inflexible con las manifestaciones culturales ya había ajustado todas las clavijas luego del golpe dentro del golpe que se da a partir del Acto Institucional número 5, de diciembre de 1968.

${ }^{28}$ Antonio Candido. Literatura e sociedade. pp. 165-167.

${ }^{29}$ Sobre las temporalidades múltiples en Candido, véase Flora Süssekind, "Relógios e ritmos. Em torno de um comentário de Antonio Candido", en A voz e a série, Rio de Janeiro/Belo Horizonte, Sette letras/Editora da UFMG, 1998.

${ }^{30}$ Cf. Paulo Eduardo Arantes, Um departamento francês de ultramar. Estudos sobre a formação da cultura filosófica USPiana (Uma experiência nos anos 60), Rio de Janeiro, Paz e Terra, 1994. Para un perfil político-académico de Candido, ver también Célia Pedrosa, Antonio Candido: a palavra empenhada, São Paulo, Edusp, 1994. 
Literatura e sociedade está compuesto, como dije que es usual en Candido, por textos que ya estaban escritos, a los que suma algunos especialmente pensados para integrar esa unidad. Por eso, si bien es un texto que acaba componiéndose, también es pensado como totalidad. Porque hay una totalidad conceptual que se urde en el montaje y la organización de las partes y que, a la vez, estructura el compuesto.

Los artículos que van a dar a otros libros concebidos más explícitamente que éste como una "coletânea", en su brevedad relativa también encierran una totalidad: pienso en "Literatura e subdesenvolvimento" o "Literatura de dois gumes", para no volver a mencionar la "Dialética da malandragem".

Candido va escribiendo por focalizaciones parciales (que no deben considerarse fragmentarias, salvo que pensemos el fragmento, al modo romántico de la escuela de Jena, como un todo) una obra crítica que se recorta sobre una totalidad virtual. Cada focalización es, a la vez, una parte que integra ese work in progress permanente que es su obra, como totalidad en marcha y proyectual. Pero cada focalización puede ser vista, también, como una pequeña totalidad, epítome del modo de conjunto (y de la coherencia) que tiene esa obra.

Leer la obra de este crítico brasileño no sólo sirve para conocer y pensar cómo funciona la literatura de su país. Nos sirve para ver cómo pensar también otras literaturas, como lo ha demostrado Ángel Rama en relación con algunas manifestaciones de la literatura rioplatense. Aparte del texto del uruguayo sobre "El sistema literario de la literatura gauchesca", que puede filiarse de modo ostensible con la idea de sistema de Candido, creo que la articulación entre gauchesca e historia que hace en "De la poesía política popular a la poesía de partido: Hilario Ascasubi y Estanislao del Campo", fundamentalmente al proponer las etapas de la gauchesca pero no sólo por eso, es - no con el mismo método crítico pero sí con los mismos eficaces resultados - una inteligentísima (y didáctica) articulación entre forma histórica y forma estética.

Fuera de algunas consideraciones centrales pero breves, como la que ya trabajé en relación con Sarmiento, y algunas otras menciones a Jorge Luis Borges, Esteban Echeverría y Rafael Obligado (en "Literatura e subdesenvolvimento") o a Cortázar (en "A nova narrativa"), Candido no se ocupó específicamente de la literatura argentina. Pero no sería para nada justo reclamárselo. Su obra sirve igual - y mostrarlo es una de las intenciones de mi artículo - para que nosotros podamos seguir pensándola. O para que encontremos en su obra nuevas posibilidades de abordaje.

Para poder pensar, entonces, la dialéctica en la relación copulativa entre civilización y barbarie porque es precisamente en esa puesta en contacto (y, por ende, en fricción pero también en contaminación) que radica lo peligroso de la dicotomía que marca a la nación argentina. Juego dialéctico que pueden poner de manifiesto incluso en sus propias trayectorias y proyectos Alberdi y Sarmiento a partir de la polémica que mantienen en 1853, encarnando respectivamente los polos del orden y del desorden entre los que va oscilando la formación cultural y política de la Argentina. ${ }^{31}$ 
La obra de Candido me permite entender incluso, aunque no sean explícitamente sus postulados los que lo hayan generado, que una Historia crítica de la literatura argentina como la que dirige precisamente Noé Jitrik pueda tener, junto con tomos que se ocupen de ciertos momentos - como una forma dinámica de la movilidad entre fases - dos tomos que no están pensados desde la idea de período sino de autor. Entonces, Sarmiento o Macedonio Fernández (que de esos tomos se trata) pueden ser pensados como momentos decisivos de la (historia de la) literatura argentina. ${ }^{32}$

Lo que en Literatura e sociedade plantea Candido respecto de la "tradição de auditório", formada por una literatura que fundamentalmente se oye o se hace oír ("A grande mayoría dos nossos escritores, em prosa e verso, fala de pena em punho e prefigura um lector que ouve o som da sua voz brotar a cada passo por entre as linhas") ${ }^{33}$, también sirve para pensar ciertas manifestaciones de la gauchesca, como los papeles de Hilario Ascasubi que se hacían circular entre los soldados durante el Sitio de Montevideo y, por supuesto, también la lectura en voz alta que se hace del Martín Fierro en la campaña para servicio de los iletrados. Pero también le es aplicable perfectamente a la gauchesca lo que Candido piensa para el indianismo cuando desmiente de modo rotundo a Capistrano de Abreu, quien filia el indianismo con lo popular, para afirmar terminante que "[a] sua raíz é erudita".

Y si, como fui proponiendo, el pensamiento crítico de Candido puede ayudar a pensar de nuevo la relación entre realidad y ficción y la articulación entre contrarios, es necesario marcar que no sólo es posible volver desde ahí a Sarmiento, a quien Candido ha colocado en un lugar central, sino también a Jorge Luis Borges, con cuyo proyecto estético ha admitido no sentir particular afinidad: "É um escritor fascinante, mas devo dizer que não tenho por ele a admiração quase fanática que despertou no Brasil. Com risco de dizer uma heresia, penso que é um grande escritor menor". ${ }^{44}$ Sin querer yo misma pecar por herejía pero tampoco por exceso de devoción, quiero proponer que tal vez sea precisamente Borges el escritor en el que mejor puedan pensarse las propuestas de Candido de superación del 2 por el 3 o las consideraciones dinámicas y sintéticas de las díadas y polarizaciones que han sido modos de indagación estructurales de la literatura desde por lo menos el siglo XVIII, como se ve en los cuentos "El Sur" o "Historia del guerrero y de la cautiva". Porque Borges entendió bien que el problema más interesante que debía plantear no era el de la exclusión sino el de la combinación de los contrarios.

${ }^{31}$ Trabajé la relación de las trayectorias y proyectos de los dos argentinos desde la dialéctica de Candido en mi tesis de doctorado sobre "La literatura del exilio en el Brasil en la época de Rosas", defendida en la Universidad de Buenos Aires en 2006 (en prensa).

${ }^{32} \mathrm{La}$ Historia crítica de la literatura argentina, que empezó a ser editada por Emecé en Buenos Aires en 1999, está compuesta por doce volúmenes, de los que ya han salido siete. La dirección general es de Noé Jitrik y cada tomo tiene, a la vez, un director.

${ }^{33}$ Antonio Candido. Literatura e sociedade, p. 81.

${ }^{34}$ Reportaje de Pablo Rocca a Antonio Candido, en Ángel Rama, Emir Rodríguez Monegal y el Brasil, p. 420 . 